\title{
Impact of allergic diseases on fertility
}

\author{
Eliza Wasilewska', Sylwia Małgorzewicz ${ }^{2}$ \\ ${ }^{1}$ Allergology and Pulmonology Department, Medical University of Gdańsk, Gdańsk, Poland \\ ${ }^{2}$ Clinical Nutrition Department, Medical University of Gdańsk, Gdańsk, Poland
}

Adv Dermatol Allergol 2019; XXXVI (5): 507-512

DOI: https://doi.org/10.5114/ada.2019.89501

\begin{abstract}
The incidence of allergic diseases has been increasing in recent decades, and currently, nearly $30 \%$ of the European population suffer from some type of allergy. Also, an increasing number of people are suffering from infertility. Both diseases are related to the hormonal and immune systems, which prompts the question as to whether there is a causal relationship between allergic disorders and the reproductive system. The purpose of this review is to evaluate whether there is a link between allergic diseases and infertility, using the available literature.
\end{abstract}

Key words: allergic diseases, rhinitis, asthma, fertility, irregular menstruation.

\section{Introduction}

Allergy is an abnormal reaction of the immune system hypersensitivity, resulting in many immunological consequences in the body. The incidence of allergic diseases has been increasing in recent decades, and currently, nearly $30 \%$ of the European population suffer from some type of allergy: rhinitis (AR), atopic asthma, bronchitis, allergic conjunctivitis (AC), atopic dermatitis (AD) [1]. The symptoms of allergy are triggered by chemicals, natural and artificial food additives, spices, pollen, mould, animal fur and other substances. The organism comes into contact with most of the above substances on a daily basis, so every day the immune system in hypersensitive people is stimulated. The consequences of the response of the immune system can be observed most often in the skin (pruritus, urticaria, eczema), digestive system (discomfort, abdominal pain, diarrhoea, constipation) and respiratory system (cough, breathlessness, rhinitis). Allergic diseases may also cause atypical symptoms, less often associated with allergies. Campbell [2] have demonstrated in their study that the headaches, irritability, decreased concentration, sleep disturbances were present in patients with allergies. There have been also haematological and other atypical symptoms such as proteinuria, pain in the bones, joints, and muscles [3]. Few studies describe the consequences of allergic diseases in the reproductive system. The response to an allergen causes a lot of reactions in the immune system, causing local inflammations. Many of the cells in an allergic response, such as mast cells, lymphocytes, Th17, interleukins, leukotrienes C4, nitric oxide (NO) are also detectable in increased concentrations in patients with fertility problems [4-8]. It is interesting that endometriosis, which is one of the more frequent causes of infertility, often coexists with allergies. It was found that women with endometriosis suffered from $A R, A D, A C$, asthma more frequently than women without fertility disorders $[9,10]$. The female reproductive system seems to be very vulnerable to lifestyle-related factors, such as alcohol consumption and smoking habits, psychological stress, night work, and hormonal, or immunological diseases. Allergic diseases cause a reduction in the quality of life due to chronic clinical signs, changing lifestyle, eating habits, and the use of drugs. They have been shown to affect fertility by means of delayed conception and an increased risk of miscarriage, or disturbed menstrual function [11]. Increase in the incidence of allergic diseases and infertility prompted the question as to whether there is a causal relationship between allergic disorders and the reproductive system. Female reproductive health could be measured in an epidemiological study by regularity of the menstrual cycle, time to pregnancy, and fertility rate.

The purpose of this review is to evaluate whether there is a link between allergic diseases and infertility, using the available literature (Table 1).

Address for correspondence: Eliza Wasilewska MD PhD, Allergology and Pulmonology Department, Medical University of Gdańsk, 7 Dębinki St, 80-211 Poland, phone: +48 726045 909, e-mail: ewasilewska@gumed.edu.pl Received: 29.12.2017, accepted: 10.05.2018. 


\section{Irregular menstruation}

Non-pregnant women of reproductive age may have irregular menstruation for a variety of reasons. Diseases of the reproductive system (endometriosis, PCOS polycystic ovarian syndrome) are common causes of changes of menstruation. It is known that endocrinology, oncology and other severe diseases, stress and medications, may cause irregular menstruation. Epidemiological studies show that irregular menstruation occurs in 15-20\% of women of reproductive age. A small number of studies define the relationship between allergies and irregular menstruation. Svanes et al. [12] evaluated personal questionnaires from 8588 women from North Europe in the RHINE study. The prevalence of irregular menstruation was $15 \%$ in women aged $25-42$ years old. The prevalence of asthma and allergy was higher in women with irregular menstruation periods. Irregular menstruation was significantly associated with an increased risk of asthma, and AR. The associations were particularly strong for asthma or wheeze preceded by AR [12]. Real et al. [13] evaluated 1631 women aged 28 to 44 years participating in the European Community Respiratory Health Survey. Long or irregular menstrual cycles were reported by 313 (19\%) women. Women with oligomenorrhea are more often diagnosed with asthma, particularly allergic asthma, independent of body mass index (BMI) and physical activity. The results of this study showed reduced lung function in women with irregular menstruation. The authors suggest that women with oligomenorrhea should be tested for asthma and lung function. Airways pathology may have not only hormonal, but also a metabolic component. In another study Galobardes et al. [14] investigated the association of age at menarche, irregular periods, duration of menstruation, and acne with a medical history of asthma and atopy (AR and/or AD/urticaria) in a historical cohort of students (who studied between 1948-1968) in the United King-

Table 1. Fertility depends on a study factor, population and type of allergic diseases

\begin{tabular}{|c|c|c|c|c|}
\hline Study (reference) & $\begin{array}{l}\text { Age of } \\
\text { patients }\end{array}$ & $\begin{array}{l}\text { Number } \\
\text { of patients }\end{array}$ & $\begin{array}{l}\text { Type of allergic } \\
\text { diseases }\end{array}$ & Result of study \\
\hline \multicolumn{5}{|l|}{ Irregular menstruation (IRM): } \\
\hline Svanes et al. 2005 [12] & $25-42$ & 8588 & $A R, A B$ & $\begin{array}{l}15 \% \text { of the study population had IRM. Women } \\
\text { with IRM had a higher prevalence of } A B \text { and } A R\end{array}$ \\
\hline Real et al. 2007 [13] & $28-44$ & 1631 & $A R, A B$ & $\begin{array}{c}19 \% \text { of the study population had IRM. Women } \\
\text { with IRM had a higher prevalence of } A B \text { and } \\
\text { reduced lung function }\end{array}$ \\
\hline Galobardes 2012 [14] & $\begin{array}{c}\text { Students } \\
\text { who studied } \\
\text { in } 1948-1968\end{array}$ & 3502 & $\begin{array}{l}\text { AR, atopic and } \\
\text { non-atopic } A B \text {, } \\
\text { AD, urticaria }\end{array}$ & $\begin{array}{l}16.4 \% \text { of the study population had IRM. Women } \\
\text { with IRM had a higher risk of atopic } A B, A R, A D\end{array}$ \\
\hline \multicolumn{5}{|l|}{ Time to pregnancy (TTP): } \\
\hline Westergaard et al. 2003 [24] & $15-43$ & 31145 & $A R$ & $\begin{array}{l}\text { Women with AR were more fertile than healthy } \\
\text { women }\end{array}$ \\
\hline Gade et al. 2014 [28] & $12-41$ & 15250 & $\begin{array}{l}\text { atopic and non- } \\
\text { atopic } A B\end{array}$ & $\begin{array}{c}\text { More asthmatic women than non-asthmatics had } \\
\text { TTP }>1 \text {. Asthma prolongs TTP. The negative effect } \\
\text { of asthma on fertility increases with age and } \\
\text { disease intensity }\end{array}$ \\
\hline \multicolumn{5}{|l|}{ Spontaneously natural abortion: } \\
\hline Westergaard et al. 2003 [24] & $15-43$ & 31145 & $A R$ & $\begin{array}{l}\text { No difference between allergic and healthy } \\
\text { women }\end{array}$ \\
\hline \multicolumn{5}{|l|}{ Fertility rate (FR): } \\
\hline Tata et al. 2007 [38] & $15-45$ & 491516 & $A R, A B, A D$ & $\begin{array}{l}\text { No difference between allergic and healthy } \\
\text { women }\end{array}$ \\
\hline Gade et al. 2014 [28] & $12-41$ & 15250 & $\begin{array}{l}\text { Atopic and non- } \\
\text { atopic AB }\end{array}$ & $\begin{array}{l}\text { No difference between allergic and healthy } \\
\text { women }\end{array}$ \\
\hline Sunyer et al. 2005 [29] & $20-44$ & 2414 & AR & $\begin{array}{l}\text { No difference between allergic and healthy } \\
\text { women }\end{array}$ \\
\hline Karmaus et al. 2003 [39] & $25-44$ & 2849 & $A R, A B, A D$ & $\begin{array}{l}\text { Atopic women had fewer children than healthy } \\
\text { women }\end{array}$ \\
\hline Forastiere et al. 2005 [41] & $35-74$ & 1755 & $A R, A B, A D$ & $\begin{array}{l}\text { FR was inversely related to lifetime clinical } \\
\text { sequelae such as } A R \text { and } A D \text {, but not to asthma }\end{array}$ \\
\hline
\end{tabular}

$A R$ - allergic rhinitis, $A B$ - asthma bronchiale, $A D$ - atopic dermatitis. 
dom. Irregular periods and earlier menarche have been associated with a higher risk of asthma and allergic diseases. The authors found an association of irregular periods with higher odds of atopic asthma and atopy alone, but not with non-atopic asthma. The authors found no association with acne, a marker of high testosterone levels. This has suggested a role of oestrogens in the development of these conditions.

Receptors for sex steroids were discovered on lymphocytes, monocytes and mast cells. These cells, after activation by the sex hormones, can interfere and affect the quality and severity of an allergic response. Oestrogen has an important role in the mechanism of allergy. Through the suppression of T cell function, oestrogens increase the number of Th2 lymphocytes; in effect, by redirecting the body's response towards the production of antibodies of IgE class and affecting the early and late phase of an allergic response $[15,16]$. It has been proven in vitro that the incubation of mast cells with oestrogen promotes their degranulation, and the release of histamine in the IgE-dependent mechanism [17]. Similarly, the incubation of mast cells, basophils and bone marrow cells with $17 \beta$ oestrogen triggers the release of allergic inflammatory mediators: $\beta$-hexosaminidase and leukotriene C4. It is important that oestrogen in these studies was at physiological concentrations in females in different periods of the cycle. Researchers have put forward a proposal that oestrogen stimulates the severity of IgE-dependent degranulation, thus enhancing the inflammatory response of the body to the allergen [18, 19]. This means that in the presence of oestrogen clinical symptoms may occur, even at small doses of the allergen. This idea is confirmed by studies demonstrating the severity of allergic reactions that occur in women with respect to the concentration of oestrogen, independent of the concentration of allergens. So far, this association has been found between menstruation, pregnancy, hormone therapy and the severity of allergic reactions [20]. It is known for peri-menstrual asthma (PMA) and severe asthma exacerbations (near fatal asthma, NFA) and anaphylaxis in the period around menstruation [21-23].

The effect of interactions between the immune system and hormones requires further research, but a relationship was found between irregular menstruation and the allergic disease such as atopic asthma, AR, AD in most epidemiological studies of women at procreative age.

\section{Time to pregnancy (TTP)}

TTP is a tool in reproductive epidemiology for measurement of fecundability (the probability of being pregnant in each cycle) by establishing how long it takes couples to conceive. Several factors were found to have an impact on TTP [11]. Some authors evaluated the association between TTP and allergy diseases. Westergaard et al. [24] analysed a cohort of 31,145 women aged 15 to 43 years; they fell into 2 groups - healthy women and those suffering from AR. Women with TTP below 1 year suffered from AR more often than women with TTP $>1$ year. Women with menarche below 12 years had AR more often than those with menarche at 14 years. It has been found that women who already bore a child are less likely to have AR. Women with AR had waited to become pregnant for a shorter time than non-allergic women. This study shows that females with AR were more fertile than women without these conditions.

A partial explanation of shorter TTP of women with $A R$ is the presence of physiologic promotion of conception in allergic women related to a balance towards Thelper 2 cells in allergic disease $[25,26]$. Enhanced Th2 activity is beneficial and observed also in physiological pregnancy. What is more, reduced activity of Th2 and lower occurrence of atopic diseases were found in women with reproduction failure [27].

Asthma was hypothesised to have a different relationship with fertility than AR or AD. In the study of Gade et al. [28], asthma was associated with an increased TTP; the percentage of asthmatics with a TTP $>1$ year was $27 \%$ versus $21.6 \%$ for non-asthmatics ( $p=0.009$ ). Untreated asthmatics had a significantly increased risk of prolonged TTP compared to healthy individuals. It is interesting that the treatment of asthma reduced the TTP [29].

The nature and degree of inflammation is independent to the phenotype of asthma.

The chronic inflammation has a large effect on fertility, increased TTP. The consequences of the inflammatory process in the lower airways in asthmatic women are an impact of inflammation on the reproductive system. This is confirmed by other studies in which women with systemic inflammation, e.g. obese women or women with a metabolic syndrome have an increased TTP [30, 31]. Metabolic syndrome is a part of polycystic ovary syndrome (PCOS), and Zieraua et al., in meta-analyses, confirmed that asthma may be associated with PCOS, and women with PCOS have a more severe type of asth$\mathrm{ma}$ [32]. Also, an interesting observation is the fact that a greater number of females undergoing in vitro fertility (IVF) treatment were using anti-asthmatic drugs [33].

\section{Spontaneous natural abortion}

Westergaard et al. have not found any difference between women with allergic rhinitis and healthy women, in terms of spontaneous miscarriage. However, in women with asthma, the risk of spontaneous miscarriage is a bit higher than in healthy women [33]. Studies have shown that untreated asthma influences the foetus during pregnancy, by increasing the risk of abortions, preterm birth, low birth weight and perinatal mortality [29, 34-37]. 


\section{Reproductive history (fertility rate)}

The fertility rate is the number of livebirths per 1,000 women. Tata et al. [38] compared fertility rates among women with asthma, eczema, or AR with those in the general female United Kingdom population using computerized primary-care data. The cohort of 491,516 women had 91,147 livebirths, and fertility rates were similar in both groups - allergic and non-allergic women. Moreover, it has been found that women with eczema and AR may have had a slightly higher fertility rate than healthy women. The conclusion of this study is that women with allergic disease do not have fewer children than women without allergic disease. Also the data of Gade et al. [28] showed that the number of offspring is similar between asthmatics and healthy subjects in a cohort of 15,250 twins living in Denmark. Sunyer et al. [29] evaluated 1,487 mothers and asked them about fertility history and allergic rhinitis. They reported an inverse association between atopy as well as allergic rhinitis and the number of offspring. But, in conclusion it has been found that although women with atopy initially had fewer children, there was no difference in the number of children after an 8-year follow-up. This means that these women, or some of them, delay the moment of procreation or have a problem with getting pregnant. However, Karmaus et al. $[39,40]$ showed that atopic individuals tend to have fewer children, and in another study, the number of livebirths was inversely related to lifetime clinical sequelae such as AR and AC, but not to asthma [41].

The results of most of the studies prove that women with allergies and asthma, in spite of systemic inflammation, do not present a reduced fertility rate. The reason may be promoted conception through increased Th2 activity.

\section{Endometriosis and allergic diseases}

Endometriosis is a condition in which the functional tissue uterus (endometrium) is present outside the uter-

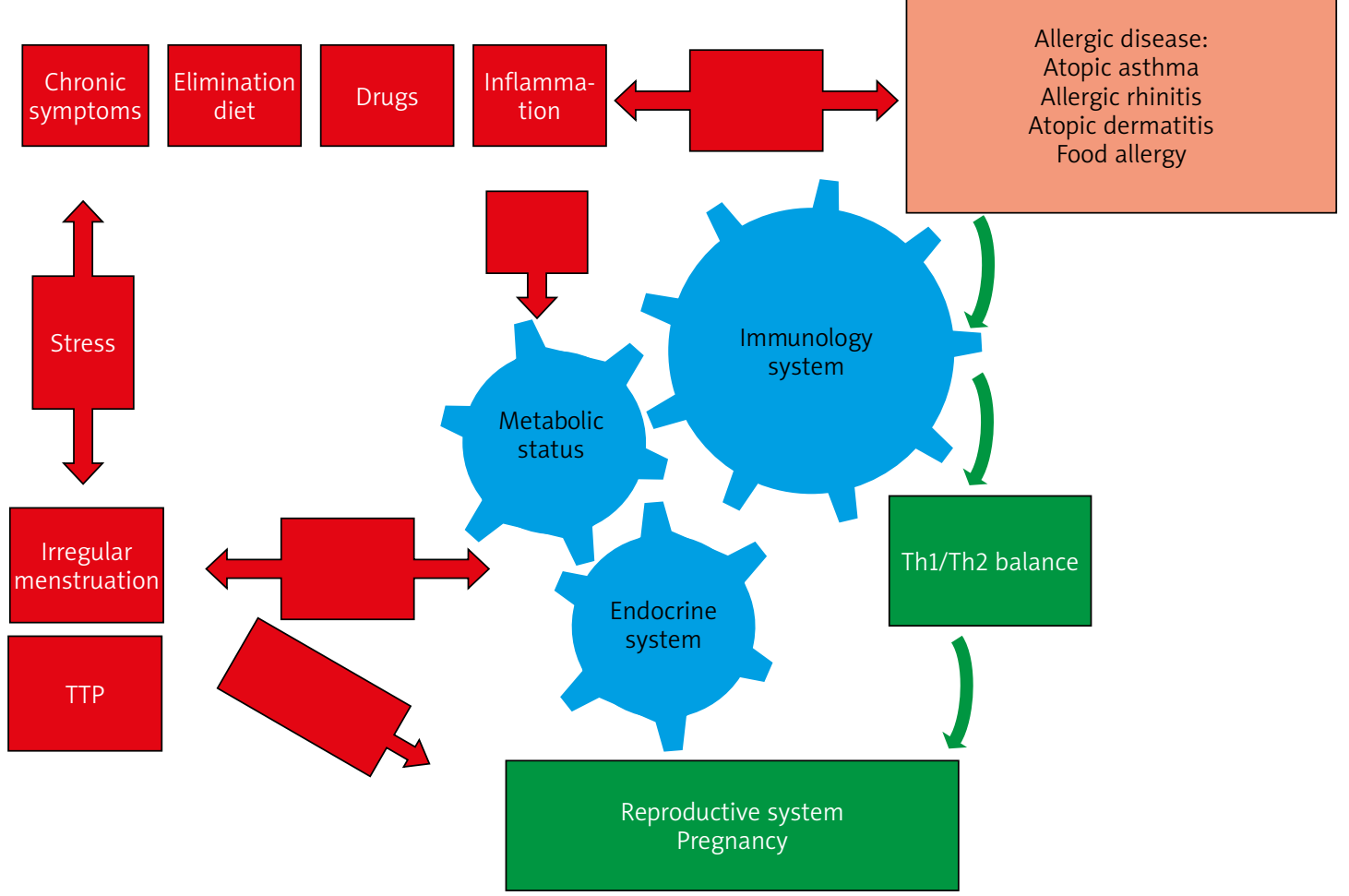

Figure 1. The pathogenetic relationship between fertility and allergic diseases. The response to an allergen causes a lot of reactions in the immune system, leading to local inflammation with the possible movement of inflammatory cells into the bloodstream. Allergic inflammation may secondarily affect the reproductive system by reactivity with sex hormones (particularly oestrogens). The result of these interactions is, on the one hand, the increase in sensitivity to allergens, and on the other hand increase in oestrogen what causes an increase of lutropin in the pituitary gland and gives signal to ovulation. In addition, the female reproductive system is vulnerable to lifestyle-related factors, such as allergic factors (elimination diets, chronic symptoms of allergy, drugs), psychological stress, etc. being able to cause irregular menstruation, and consequently a longer TTP. On the other hand, it seems that the detuning to Th2 trail facilitates procreation. As a result, women with allergies are pregnant and have the same number of offspring as healthy women, despite irregular periods and a longer TTP 
ine cavity in the pelvis, or in other locations. Most women with endometriosis suffer from pelvic pain, menstrual disorders, and severe pain during ovulation and during sexual intercourse. Endometriosis affects $5-18 \%$ of women of childbearing age, out of which 30-50\% suffer from infertility [42]. The results of many studies showed that patients with endometriosis have a higher prevalence of allergies, and the coexistence of both allergies and autoimmune diseases. In 1981, for the first time, the increased incidence of allergic diseases, autoimmune and malignant tumours was described in women diagnosed with endometriosis [43]. Subsequent studies have confirmed the validity of this observation [9, 44-46]. Caserta et al. [47] evaluated 304 patients with endometriosis, and 318 without endometriosis, and stated that patients with endometriosis have a higher prevalence of allergies ( $p=0.0003$ ), and coexistence of allergies and autoimmune diseases ( $p=0.0274)$. An association between endometriosis and allergic diseases has been confirmed in a study of Matalliotakis et al. [44]. Five hundred and one patients with endometriosis, in comparison to 188 controls, had had significant excesses identified for medications, sinus allergic rhinitis, and asthma. Also, women with endometriosis were significantly more likely to report a positive family history of allergies. A meta-analysis by Bungum et al. [10] confirmed the relationship between allergies including $A R$, sinus allergic rhinitis, food intolerance/sensitivities (food allergy) and endometriosis.

A common mechanism of allergy and endometriosis can be produced by several cell types, cytokines accompanying allergic inflammation, which also were found in endometriosis. Missmer and Cramer [42] showed an increase in the concentration of leukocytes, macrophages and lymphocytes in the peritoneal fluid in women with endometriosis. The consequence of these studies is the concept that the balance between immune response Th1 and Th2, in women with endometriosis, moves toward Th2, while promoting the development of allergic reactions [48]. A potential mechanism for the creation of endometriosis starts the activation of macrophages in the peritoneal cavity, which in turn produces numerous growth factors and cytokines produced by several cell types (for example, tumor necrosis factor $\alpha$ (TNF- $\alpha$ ) and interleukin $1 \beta(\mathrm{IL}-1 \beta))$, released into the peritoneal fluid. TNF- $\alpha$ and IL-1 $\beta$ stimulate the synthesis of molecules regulated on activation, normal T-cell expressed and secreted (RANTES) and monocyte chemotactic protein-1 (MCP-1) in endometrial cells. As a result, their actions are followed by the recruitment of macrophages in the implant of the endometrium and the production of the histamine releasing factor (HRF) which enhances the production of IL-4 and IL-13, and plays an important role in allergic rhinitis by promoting allergic phenotype [49, 50]. Previous studies can, in part, explain the increased risk of developing allergic diseases, in women diagnosed with endometriosis [44-46]. Still, the association between endometriosis, allergy and fertility is unknown.

\section{Conclusions}

The presented studies indicate a possible association between allergic diseases and fertility of women.

It follows that allergic women have more irregular menstruation and longer TTP. However, allergic disease has no effect on the fertility rate, and the number of offspring, which is similar to that in healthy women. The mechanism between fertility and allergic diseases has not yet been completely clarified (Figure 1). It seems that this is a result of the activation of Th2, which is conducive to reproduction. On the other hand, interesting is the presence of an increased number of women with both allergies and endometriosis, where reduced fertility is accompanied by a Th2 response.

A different mechanism on fertility is caused by asthma. Uncontrolled, untreated or difficult-to-treat asthma, regardless of atopy, causes systemic inflammation; and in women with $A R, A D$, irregular menstrual periods, and longer TTP were observed more often. A higher incidence of infertility was also found in obese women, or women with metabolic syndrome, as well as asthma.

The final assessment of the relation of allergies and fertility is difficult due to the complicated and multi-factorial mechanism of both diseases, and this should be the subject of further research.

\section{Conflict of interest}

The authors declare no conflict of interest.

\section{References}

1. Warner JO, Kaliner MA, Crisci CD, et al. Allergy practice worldwide: a report by the world allergy organization specialty and training council. Int Arch Allergy Immunol 2006; 139: 166-74.

2. Campbell MB. Neurological and psychiatric aspects of allergy. Otolaryngol Clin North Am 1974; 7: 805-25.

3. Borish L. Allergic rhinitis: systemic inflammation and implications for management. J Allerg Clin Immunol 2003; 112: 1021-31.

4. Jensen-Jarolim E, Untersmayr E. Gender-medicine aspects in allergology. Allergy 2008; 63: 615-8.

5. Gade EJ, Thomsen SF, Lindenberg S, et al. Lower values of VEGF in the endometrial lining are a possible cause of reduced fertility in asthmatic patients. Eur Respir J 2014; 44: 4076-78.

6. Sugumata M, Ihara T, Uchiide I. Increase of activated mast cells in human endometriosis. Am J Reprod Immunol 2005; 53: 120-5.

7. Telfer JF, Lyall F, Norman JE, Cameronet IT. Identification of nitric oxide synthase in human uterus. Hum Reprod 1995; 10: $19-23$

8. Wu MY, Chao KH, Yang JH, et al. Nitric oxide synthesis is increased in the endometrial tissue of women with endometriosis. Hum Reprod 2003; 18: 2668-71. 
9. Sinaii N, Cleary SD, Ballweg ML, et al. High rates of autoimmune and endocrine disorders, fibromyalgia, chronic fatigue syndrome and atopic diseases among women with endometriosis: a survey analysis. Hum Reprod 2002; 17: 2715-24.

10. Bungum HF, Vestergaard C, Knudsena UB. Endometriosis and type 1 allergies/immediate type hypersensitivity: a sys tematic review. Eur J Obs Gyn Rep Biol 2014; 179: 209-15.

11. Axmon A, Rylander L, Albin M, Hagmar L. Factors affecting time to pregnancy. Hum Reprod 2006; 21: 1279-84.

12. Svanes C, Real FG, Gislasonetal T, et al. Association of asthma and high fever with irregular menstruation. Thorax 2005; 60: 445-50.

13. Real FG, Svanes C, Omenaas ER, et al. Menstrual irregularity and asthma and lung function. J Allergy and Clin Immuno 2007; 120: 557-64.

14. Galobardes B. The association between irregular menstruations and acne with asthma and atopy phenotypes. Am J Epidemiol 2012; 176: 733-7.

15. Lang TJ. Estrogen as an immunomodulator. Clin Immunol 2004; 113: 224-30.

16. Zhao XJ, McKerr G, Dong Z, et al. Expression of oestrogen and progesterone receptors by mast cells alone, but not lymphocytes, macrophages or other immune cells in human upper airways. Thorax 2001; 56: 205-11.

17. Cocchiara R, Albeggiani G, Di Trapani G, et al. Oestradiol enhances in vitro the histamine release induced by embryonic histamine-releasing factor (EHRF) from uterine mast cells. Hum Reprod 1992; 7: 1036-41.

18. Zaitsu M, Narita S, Lambert KC, et al. Estradiol activates mast cells via a nongenomic estrogen receptor-alpha and calcium influx. Mol Immunol 2007; 44: 1977-85.

19. Eisenberg SW, Cacciatore G, Klarenbeek S, et al. Influence of 17 beta-oestradiol, nortestosterone and dexamethasone on the adaptive immune response in veal calves. Res Vet Sci 2008; 84: 199-205.

20. Speizer FE, Willett WC, Trichopoulos D, et al. Menopause, postmenopausal estrogen preparations, and the risk of adult-onset asthma. A prospective cohort study. Am J Respir Crit Care Med 1995; 152: 1183-8.

21. Martinez-Moragon E, Plaza V, Serrano J, et al. Near-fata asthma related to menstruation. J Allergy Clin Immuno 2004; 113: 242-4.

22. Vrieze A, Postma DS, Kerstjens HA. Perimenstrual asthma: a syndrome without known cause or cure. J Allergy Clin Immunol 2003; 112: 271-82.

23. Dratva J, Schindler C, Curjuric I, et al. Perimenstrual increase in bronchial hyperreactivity in premenopausal women: results from the population-based SAPALDIA 2 cohort. J Allergy Clin Immunol 2010; 125: 823-9.

24. Westergaard T, Begtrup K, Rostgaard K, et al. Reproductive history and allergic rhinitis among 31145 Danish women. Clin Exp Allergy 2003; 33: 301-5.

25. Makhseed M, Raghupathy R, Azizieh F, et al. Th1 and Th2 cytokine profiles in recurrent aborters with successful pregnancy and with subsequent abortions. Hum Reprod 2001; 16: 2219-6.

26. Piccinni MP, Scaletti C, Maggi E, et al. Role of hormone-controlled Th1- and Th2-type cytokines in successful pregnancy. J Neuroimmunol 2000; 109: 30-3.

27. Hanzlikova J, Ulcova-Gallova Z, Malkusova I, et al. Th1 - Th2 response and the atopy risk in patients with reproduction failure. Am J Reprod Immunol 2009; 61: 213-20.

28. Gade EJ, Thomsen SF, Lindenberg S, et al. Asthma affects time to pregnancy and fertility: a register-based twin study. Eur Respir J 2014; 43: 1077-85.
29. Sunyer J, Anto JM, Plana E, et al. Maternal atopy and changes in parity. Clin Exp Allergy 2005; 35: 1028-32.

30. Gesink DC, Law RF, Maclehose MP, et al. Obesity and time to pregnancy. Hum Reprod 2007; 22: 414-20.

31. Brumpton BM, Camargo CA Jr, Romundstad PR, et al. Metabolic syndrome and incidence of asthma in adults: the HUNT study. Eur Respir J 2013; 42: 1495-502.

32. Zieraua L, Gade EJ, Svend L, et al. Coexistence of asthma and polycystic ovary syndrome: a concise review. Respir Med 2016; 119: 155-15.

33. Källén B, Otterblad OP. Use of anti-asthmatic drugs during pregnancy. 1. Maternal characteristics, pregnancy and delivery complications Eur J Clin Pharmacol 2007; 63: 363-6.

34. Blais L, Kettani FZ, Forget A. Relationship between maternal asthma, its severity and control and abortion. Hum Reprod 2013; 28: 908-15.

35. Gade EJ. Female asthma has a negative effect on fertility: what is the connection? ISRN Allergy 2014; 2014: 131092.

36. Kaandorp SP, van Mens TE, Middeldorp S, et al. Time to conception and time to live birth in women with unexplained recurrent miscarriage. Hum Reprod 2014; 29: 1146-52.

37. Sheiner M, Mazor A, Levy A, et al. Pregnancy outcome of asthmatic patients: a population-based study. J Matern Fetal Neonatal Med 2005; 18: 237-40.

38. Tata LJ, Hubbard RB, McKeever TM, et al. Fertility rates in women with asthma, eczema, and hay fever: a general population-based cohort study. Am J Epidemiol 2007; 165: 1023-30.

39. Karmaus W, Eneli I. Maternal atopy and the number of offspring: is there an association? Pediatr Allergy Immunol 2003; 14: 470-4.

40. Karmaus W, Juul S. Infertility and subfecundity in population-based samples from Denmark, Germany, Italy, Poland and Spain. Eur J Public Health 1999; 9: 229-35.

41. Forastiere F, Sunyer J, Farchi S, et al. Number of offspring and maternal allergy. Allergy 2005; 60: 510-4.

42. Missmer SA, Cramer DW. The epidemiology of endometriosis. Obstet Gynecol Clin North Am 2003; 30: 1-19.

43. Dmowski WP, Steele RW, Baker GF. Deficient cellular immunity in endometriosis. Am J Obstet Gynecol 1981; 141: 377-83.

44. Matalliotakis I, Cakmak H, Matalliotakis M, et al. High rate of allergies among women with endometriosis. Human Repr 2012; 32: 291-3.

45. Lamb K, Nichols TR. Endometriosis: a comparison of associated disease histories. Am J Prev Med 1986; 2: 324-9.

46. Nichols TR, Lamb K, Arkins JA. The association of atopic diseases with endometriosis. Ann Allergy 1987; 59: 360-3.

47. Caserta D, Mallozzi M, Pulcinelli FM, et al. Endometriosis allergic or autoimmune disease: pthogenetic aspects a case control study. Clin Experimental Obst Gynecol 2016; 43: 354-7.

48. Podgaec S, Abrao MS, Dias JA Jr, et al. Endometriosis: an inflammatory disease with a Th2 immune response component. Hum Reprod 2007; 22: 1373-9.

49. Oikawa K, Kosugi Y, Ohbayashi T, et al. Increased expression of IgE-dependent histamine-releasing factor in endometriotic implants. J Pathol 2003; 199: 318-23.

50. Schroeder JT, Lichtenstein LM, MacDonald SM. Recombinant histamine-releasing factor enhances IgE-dependent IL-4 and IL-13 secretion by human basophils. J Immunol 1997; 159: 447-52. 